\title{
A MARCAÇÃO DE COMPOSTOS ORGÂNICOS
}

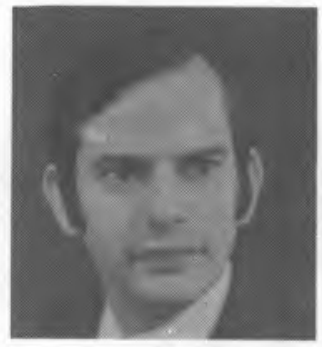

por H. M. Novais

Instituto Superior

Técnico

Lisboa

Grande parte dos elementos, tal como aparecem na Natureza, são constituídos por várias espécies nuclearmente distintas com abundâncias determinadas, genericamente designadas por núclidos; os de igual número atómico (mesmo número de protões) designam-se em particular por isótopos (de um dado elemento). Assim, enquanto que, po: exemplo, o elemento cloro aparece naturalmente constituído por dois núclidos (isótopos naturais) de números de massa 35 e 37 e abundâncias respectivamente de $75,5 \%$ e $24,5 \%$, o fluor natural é constituído apenas por um único núclido de número de massa 19. Os núclidos podem ser estáveis, tal como os acabados de mencionar, ou radioactivos; estes, por sua vez, podem, em certos casos, existir naturalmente, mas a grande maioria dos núclidos radioactivos conhecidos apenas podem ser produzidos artificialmente através de reacçõesonucleares. Deste modo, os compostos tal como existem na Natureza ou como são normalmente preparados no laboratório ou na indústria, são constituídos pelos vários elementos com a composição isotópica natural. Acontece que, para certos fins, sobretudo em investigação em química, biologia, medicina, agronomia, etc., interessa por vezes ter presente, um dado núclido (estável ou radioactivo) incluso num composto determinado. Isto pode ser importante, porque permite seguir ou traçar o caminho que esse núclido vai percorrer num dado sistema, tornando o composto em que se encontra integrado (ou um seu produto de transformação) facilmente reconhecível em dado passo do processo a que ele se encontra sujeito.

Com este fim, pode recorrer-se à marcação através dum núclido radioactivo do elemento em causa ou desse mesmo elemento enriquecido num dos seus núclidos estáveis. Também se pode efectuar em certos casos uma marcação através da introdução na molécula de um grupo de átomos, usualmente um grupo alquilo, se bem que neste caso haja que atender ao facto de se passar a ter um composto diferente, pelo que os resultados obtidos deverão ser interpretados em conformidade; não trataremos contudo aqui deste processo de marcação.

A detecção do núclido pode ser feita por espectrometria de massa, se for estável, ou por detecção das radiações que emite, se for radioactivo.

Conquanto frequentemente os núclidos radioactivos sejam usados em formas químicas simples, tais como sais inorgânicos ou colóides, por vezes interessa usá-los integrados em moléculas mais ou menos complexas, em geral de compostos orgânicos. Trataremos em especial neste artigo da marcação de compostos orgânicos com núclidos radioactivos, por envolver técnicas que não são por vezes convencionais.

Entre os núclidos radioactivos mais frequentemente usados como marcadores de compostos orgânicos contam-se o ${ }_{1}^{3} \mathrm{H}$ (trítio), o ${ }_{6}^{14} \mathrm{C}, \mathrm{o}_{15}^{32} \mathrm{P},{ }_{16}^{35} \mathrm{~S},{ }_{17}^{38} \mathrm{Cl}, \mathrm{o}{ }_{35}^{82} \mathrm{Br}$ e o ${ }_{53}^{131}$. Dos estáveis salientam-se o ${ }_{1}^{2} \mathrm{H}$ (deutério), o ${ }_{6}^{13} \mathrm{C}$, o ${ }_{7}^{15} \mathrm{~N}$ e o ${ }_{7}^{18} \mathrm{O}$. Pretende-se evidentemente que o composto marcado apresente as mesmas propriedades quimicas que o composto não marçado e que, por conseguinte, tenha exactamente o mesmo destino; isto só acontece se o núclido usado tiver uma massa atómica não muito diferente da do elemento que foi substituir o que, em geral, se verifica em primeira aproximação. Exceptua-se, em particular, o caso do trítio que, com um número de massa 3, ao ir substituir num dado composto o hidrogénio natural, de massa atómica pouco superior à unidade poderá, em certos casos, conferir um comportamento cinético diferente a esse composto marcado; o mesmo se p ?deria dizer em relação ao deutério. Designa-se este facto por efeito isotópico cinético, cujo estudo está, contudo, fora do âmbito do presente artigo.

Os métodos de marcação de compostos com núclidos radioactivos incluem, por ordem sensivelmente decrescente de importância, os seguintes:

- sintese quimica;

- permuta isotópica;

- biossintese;

- métodos radioquímicos.

Obviamente o núclido radioactivo mais versátil para a marcação de compostos orgânicos é ${ }_{0}^{14} \mathrm{C}$ que apresenta um período de semidesintegração $\mathrm{T}=5740$ anos e é um eŕnissor $\beta$ puro de baixa energia $\left(E_{\max }=0,2 \mathrm{MeV}\right)$. A marcação faz-se neste caso essencialmente por sintese química embora também se recorra por vezes à biossintese, sobretudo quando se trata da marcação de moléculas complexas produzidas por seres vivos. $\mathrm{O}_{6}^{14} \mathrm{C}$ pode obter-se por irradiação neutrónica de alvos contendo azoto (nitreto de alumínio, ṇitrato de amónio) pela reacção nuclear:

$$
{ }_{17}^{14} \mathrm{~N}(\mathrm{n}, \mathrm{p}){ }_{6}^{14} \mathrm{C}
$$

e é usualmente comercializado, como matéria prima, sob a forma de carbonato de bário ${ }^{14} \mathrm{C}$. 
A sintese de compostos marcados $\operatorname{com}{ }^{14} \mathrm{C}$ exige em geral que se trabalhe numa linha de vácuo, dadas as quantidades muito pequenas do radionúclido a manipular e dada a necessidade de se obterem rendimentos tão bons quanto possivel, devido ao elevado custo do ${ }^{14} \mathrm{C}$. A dificuldade de uma dada sintese pode variar muito segundo a posição da molécula que se pretende marcar, tendo esta questão muita importância, sobretudo quando o composto marcado se destina ao estudo de mecanismos reaccionais em química orgânica ou bioquímica.

Exemplificaremos com a-sintese do ácido malónico que se pode obter marcado no átomo de carbono carboxílico ou metilénico.

Em qualquer caso, a 1. operação a promover consiste nà transformação do carbonato de bário $-{ }^{14} \mathrm{C}$ em dióxido de carbono $-{ }^{14} \mathrm{C}$ na linha de vazio, o qual pode ser condensado numa ampola sob a forma de neve carbónica, arrefecendo-a, poí exemplo, com azoto liquido:

$$
\mathrm{Ba}^{14} \mathrm{CO}_{3}+\mathrm{H}_{2} \mathrm{SO}_{4} \rightarrow{ }^{14} \mathrm{CO}_{2}+\mathrm{BaSO}_{4}+\mathrm{H}_{2} \mathrm{O}
$$

a) Marcação do átomo de carbono carboxílicò

$$
\begin{aligned}
& { }^{14} \mathrm{CO}_{2}+\mathrm{CH}_{3} \mathrm{MgI} \longrightarrow \underset{\text { èer }}{\longrightarrow} \\
& \mathrm{CH}_{3}{ }^{14} \mathrm{COOMgI} \underset{\mathrm{H}, \mathrm{O}^{\circ}}{\longrightarrow} \mathrm{CH}_{3}{ }^{14} \mathrm{COOH} \underset{\mathrm{PCl}_{3}}{\stackrel{\mathrm{Cl}_{2}}{\longrightarrow}} \\
& \longrightarrow \mathrm{ClCH}_{2}{ }^{14} \mathrm{COOH} \stackrel{\mathrm{NaCN}}{\longrightarrow} \\
& \mathrm{NCCH}_{2}{ }^{14} \mathrm{COOH} \underset{\mathrm{U}_{2} \mathrm{O}}{\mathrm{HCl}} \mathrm{HOOCCH}_{2}{ }^{14} \mathrm{COOH}
\end{aligned}
$$

Dispondo-se de cianeto de sódio marcado $\mathrm{N} \equiv{ }^{14} \mathrm{CNa}$ poderia usar-se uma via alternativa:

\section{$\mathrm{ClCH}_{2} \mathrm{COONa}+\mathrm{Na}^{14} \mathrm{CN} \rightarrow$}

$$
\mathrm{N}^{14} \mathrm{CCH}_{2} \mathrm{COONa} \underset{\mathrm{H}_{2} \mathrm{O}}{\stackrel{\mathrm{NaOH}}{\longrightarrow}} \mathrm{NaOO}^{14} \mathrm{CCH}_{2} \mathrm{COONa} \rightarrow
$$$$
\stackrel{\mathrm{CaCl}_{2}}{\longrightarrow}\left(\mathrm{CH}_{2} \stackrel{14}{-} \mathrm{COO}\right)=\mathrm{Ca}^{++} \longrightarrow \mathrm{HOO}^{14} \mathrm{CCH}_{2} \mathrm{COOH}
$$

Esta via é claramente preferível à anterior por se introduzir o núclido marcador numa fase mais adiantada da sintese, o que deve constituir uma regra geral a aplicar, sempre que possivel, quando se pretende fazer uma marcação; neste caso, não só se realizam menos passos do que na sintese anterior como também são de natureza menos complexa, conduzindo a rendimentos mais elevados.

b) Marcação no átomo de carbono metilénico

Neste caso tem necessariamente de se passar pelo ácido cloroacético já marcado, pelo que a síntese é mais longa, envolvendo compostos marcados e o produto torna-se assim necessariamente mais dispendioso:

$$
\begin{aligned}
& { }^{14} \mathrm{CO}_{2} \stackrel{\mathrm{LiAlH}_{4}}{\longrightarrow}{ }^{14} \mathrm{CH}_{3} \mathrm{OH}^{\stackrel{\mathrm{Pl}_{3}}{\longrightarrow}}{ }^{14} \mathrm{CH}_{3} \mathrm{I} \stackrel{\mathrm{KCN}}{\longrightarrow} \\
& { }^{14} \mathrm{CH}_{3} \mathrm{CN} \stackrel{\mathrm{H}_{2} \mathrm{O}}{\longrightarrow} \mathrm{CH}_{3} \mathrm{COOH} \stackrel{\mathrm{Cl}_{2}}{\longrightarrow}{ }^{14} \mathrm{CH}_{2} \mathrm{ClCOOH} .
\end{aligned}
$$

A partir deste ponto a síntese poderia prosseguir tal como no caso anterior.

Quando se trata de marcar moléculas complexas que sejam sintetizadas por seres vivos, torna-se por vezes mais económico e prático recorrer à biossintese que consiste, em geral, em fornecer o núclido radioactivo numa forma quimica adequada ao organismo vivo pluri ou unicelular (animal ou planta) ou a um órgão isolado mantido em funcionamento ou ainda a uma solução ou suspensão de um enzima purificado. O sistema biológico seleccionado irá incorporar o núclido radioactivo biossinteticamente na substância que se pretende marcar e que é normalmente produzida por esse sistema. O principal inconveniente desta técnica é que o organismo raramente sintetiza selectivamente a substância que se pretende obter marcada, produzindo antes misturas mais ou menos complexas de substâncias, todas também marcadas, que terão de ser posteriormente separadas quimicamente; tal inconveniente não existe, contudo, no método enzimático que, em geral, é específico de uma dada transformação bioquímica. Um exemplo ilustrativo e bem conhecido é o da alga unicelular Chlorella vulgaris a qual, desenvolvida numa atmosfera de ${ }^{14} \mathrm{CO}_{2}$, incorpora por via fotossintética o núclido radioactivo nas proteínas e gorduras que elabora. A hidrólise das proteínas conduz a. uma mistura de aminoácidos uniformemente marcados com ${ }^{14} \mathrm{C}$ que podem ser separados e purificados por métodos cromatográficos. Das gorduras, obtêm-se os ácidos oleico, linoleico, linolénico, esteárico e palmítico uniformemente marcados com ${ }^{14} \mathrm{C}$. Eventualmente, outros produtos orgânicos podem também ser obtidos marcados com ${ }^{14} \mathrm{C}$ pelo processo biossintético, tais como ácidos nucleicos e hidratos de carbono, conseguindo-se assim, tanto quanto possível, um aproveitamento máximo do núclido fornecido. A biossíntese pode ser decisiva na produção de produtos naturais opticamente activos, por conduzir estereoespecificamente ao enantiómero marcado que é, por vezes, muito mais útil em investigação do que a modificação racémica que se obtem ordinariamente por via quimica; tal é o caso dos aminoácidos sintetizados pela Chlorella, todos pertencentes à série L. Contudo, é de notar que a biossintese conduz geralmente a uma marcação homogénea das moléculas, isto é, por exemplo, todos os átomos de carbono dos aminoácidos do caso anterior podem aparecer marcados, o que pode ser inconveniente em certas aplicações. Isto só não acontece se a molécula a marcar apresentar um só átomo do elemento correspondente ao núclido que se pretende introduzir, como é o caso do enxofre o qual, fornecido sob a forma de ${ }^{35} \mathrm{SO}_{4}^{\bar{a}}$ à Chlorella, permitirá o isolamento de cisteína e de metionina marcadas com ${ }^{35} \mathrm{~S}$. Outro exemplo consiste na obtenção de vitamina $\mathrm{B}_{12}$ marcada com ${ }^{57} \mathrm{Co}(\mathrm{T}=270$ dias $)$ ou com ${ }^{58} \mathrm{Co}(\mathrm{T}=70,8$ dias $)$; a respectiva biossintese é realizada por um processo aeróbio promovido pelo Sheptomyces olevaceus; a vitamina $\mathrm{B}_{12}$ é extraida para a fase aquosa aquecendo-se a suspensão celular a $80^{\circ} \mathrm{C}$ em meio ácido diluído e separada e purificada por extracção por solventes e cromatografia. Também se 
obtém selectividade na marcação se o percursor marcado for suficientemente específico para apenas intervir numa fase tardia da biossintese (caso dos enzimas).

$\mathrm{O}$ trítio ${ }_{1}^{3} \mathrm{H}$ é um núclido radioactivo emissor $\beta$ - puro de baixa energia $\left(E_{\max }=0,02 \mathrm{MeV}\right)$ e $\mathrm{T}=12,3$ anos, bastante usado na marcação de compostos orgânicos. Obtém-se através da seguinte reacção nuclear:

$$
{ }_{3}^{6} \mathrm{Li}(\mathrm{n}, \alpha){ }_{1}^{3} \mathrm{H}
$$

A marcação com ${ }_{1}^{3} \mathrm{H}$ pode fazer-se pelo chamado método de Wilzbach, método radioquímico de marcação em que a permuta é catalisada pela própria radiação do títrio. O composto a marcar é simplesmente introduzido num recipiente fechado juntamente com alguns curie de tritio molecular gasoso com um enriquecimento isotópico mínimo de $95 \%$, durante algumas horas a algumas semanas, conforme o caso. Terminada a incubação o trítio em excesso é eliminado, assim como o trítio móvel que é retirado por permutas sucessivas com água ou outro solvente hidroxílico. Como no decurso da exposição, além da permuta isotópica, se dá também uma decomposição radiolítica mais ou menos extensa com formação de vários produtos igualmente tritiados, há que efectuar sempre uma purificação bastante rigorosa por cromatografia, cristalização, etc. As actividades específicas obtidas não são em regra muito elevadas, excepto se, por exemplo, o composto contiver ligações insaturadas, caso em que haverá então adição de trítrio a essas ligações, obtendo-se um bom rendimento no produto tritiado saturado correspondente. A importância desta técnica reside na sua versatilidade - é em princípio aplicável a qualquer composto que possua hidrogénio na sua estrutura, conquanto o resultado da marcação frequentemente seja pobre - e na possivel aplicação a casos em que os compostos não possam ser marcados doutra maneira por serem sensíveis ao calor como, por exemplo, o ácido desoxiribonucleico (ADN). Outros compostos que têm sido marcados por esta técnica, sem grandes inconvenientes são, por exemplo, o ácido benzóico, a sacarose, o colesterol, a digitoxina, além de vários alcalóides, hormonas e antibióticos. Uma técnica mais rápida de introduzir trítrio, embora os resultados obtidos, tal como no caso anterior, não sejam facilmente previsiveis, consiste justamente em aquecer a $125^{\circ} \mathrm{C}$ a substância a marcar (cerca de 0,1 a $1 \mathrm{~g}$ ) na presença de água tritiada ou de ácido acético tritiado e de um catalisador, usualmente de platina ou paládio, durante 16 a 20 horas. Após evaporação do solvente, o trítio móvel é retirado por lavagem com água e o produto purificado. As actividades específicas assim como os rendimentos de incorporação do trítio são por este processo em geral supeiores às do método de Wilzbach. Contudo, a utilização de água tritiada $\left(\mathrm{T}_{2} \mathrm{O}\right)$ de elvadá actividade específica $(>40 \mathrm{Ci} / \mathrm{g})$ impõe a tomada de sérias precauções devido ao risco de explosão do vaso selado onde se faz a reacção, em virtude da intensa libertação de produtos gasosos provenientes da auto-radiólise da água tritiada, além de que a água tritiada é mais difícil de manipular e perigosa, sob o ponto de vista de contaminação, do que o tritio gasoso. A marcação com trítio de uma molécula numa posição de hidrogénio móvel, isto é, de propriedades ácidas, é fácil, bastando uma sim- ples dissolução do composto em água tritiada. Não obstante, um composto assim marcado não tem em geral interesse prático, exactamente por permutar com facilidade esse mesmo átomo, excepto em casos especiais, como seja, por exemplo, a sintese de um composto por descarboxilação de um ácido carboxílico previamente tritiado, caso em que o trítio acaba então por ficar incluído na cadeia principal da molécula:<smiles>O=C1NC(=O)C(Br)C(C(=O)O)N1</smiles><smiles>[3H]C1NC(=O)NC(=O)C1Br</smiles>

5 - bromouracilo tritiado

Outro exemplo, consiste na preparação de metanol tritiado no grupo metilo, marcação que se consegue efectuar elegantemente através da esterificação do ácido $\beta$ naftóico com diazometano seguida de saponificação do éster metílico:

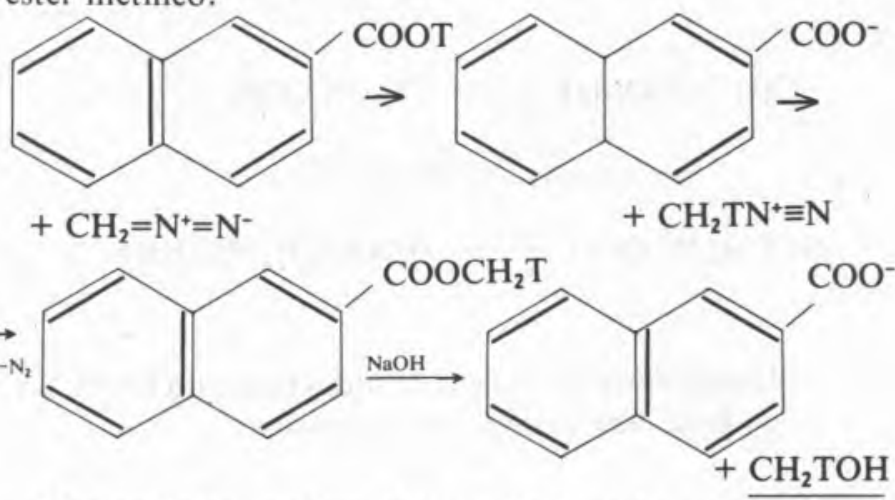

Por analogia, podem obter-se hidrocarbonetos tritiados por hidrólise de compostos organomagnesianos (Grignard) em água tritiada:

$$
\mathrm{RMgBr}+\mathrm{T}_{2} \mathrm{O} \rightarrow \underline{\mathrm{RT}}+\mathrm{MgBrOT}
$$

A permuta isotópica consiste em substituir directamente numa molécula um dos seus átomos por um seu núclido radioactivo, usualmente numa forma química diferente, quando ambos são postos em contacto; para tal torna-se necessário fornecer uma certa energia de activação quer sob a forma de calor (agitação térmica), de ultra-sons, de micro-ondas ou de radiação electromagnética (em particular, ultravioleta) ou corpuscular, caso este já atrás referido (método de Wilzbach). Na maioria dos casos em que a permuta é rápida, existem reacções reversíveis conhecidas que explicam a permuta; por exemplo, o iodeto e o iodo molecular permutam tão rapidamente à temperatura ambiente, que a velocidade não pode ser medida; esta permuta interpreta-se como ocorrendo através do equilibrio:

$$
\mathrm{I}^{-}+\mathrm{I}_{2} \rightleftarrows \mathrm{I}_{3}^{-}
$$

O mesmo acontece com o cloro e com o bromo. A permuta isotópica tem sido sobretudo usada nas marcaçōes 
com iodo $\left({ }^{131} \mathrm{I},{ }^{125} \mathrm{I}\right)$ de moléculas orgânicas contendo já iodo; são exemplos certos aminoácidos e hormonas como a 3,5-di-iodotirosina, a tri-iodotironina e a tiroxina, assim como o sal de sódio do ácido o-iodo-hipúrico (hipurano) e a tetraclorotetra-iodofluorosceina (rosa bengal) com aplicações em diagnóstico médico. De notar que não existem condições uniformes para as quais a permuta se realize nos vários casos, no que diz sobretudo respeito ao meio (aquoso, misto ou não aquoso), ao $\mathrm{pH}$, à temperatura, às concentrações e ao tempo de contacto, as quais devem ser rigorosamente estabelecidas para cada caso particular por forma a optimizar o rendimento da marcação.

Quanto o composto não possui iodo na sua estrutura, a iodação efectua-se por reacção directa do reagente (iodo, monocloreto de iodo, ou outro) com o substrato a marcar, como por exemplo, na iodação da tirosina que apresenta duas posições particularmente activadas no anel aromático, adjacentes ao grupo-OH, susceptíveis de ataque,

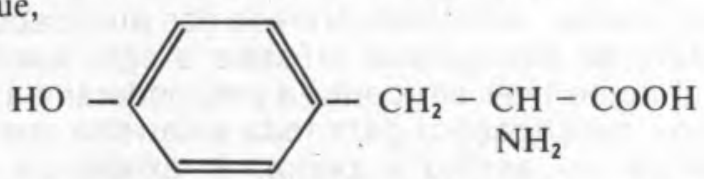

reacção esta que constitui a base fundamental da iodação das proteinas que, como a albumina, incluem este aminoácido na sua estrutura. Outras reacções de halogenação úteis não só na iodação como também na cloração e na bromação radioactivas são a adição a ligações duplas, caso da iodação do ácido oleico e da trioleina e a reacção de Sandmeyer, quando se parte de uma amina aromática primária.

Em qualquer caso, há que promover sempre uma purificação final do composto marcado, em particular no que respeita à ausência do halogénio inorgânico usado para a marcação.

A adição a ligações múltiplas é ainda extensivel à marcação com outros núclidos radioactivos como seja, o mercúrio, na obtenção de 1 - bromomercúrio - 2 t hidroxipropano (BMHP) marcado pelo ${ }^{197} \mathrm{Hg}(\mathrm{T}=64 \mathrm{~h})$ ou pelo ${ }^{203} \mathrm{Hg}(\mathrm{T}=46,6$ dias $)$ de interesse em medicina:

$$
\mathrm{CH}_{3} \mathrm{CH}=\mathrm{CH}_{2}+\mathrm{Hg}^{*}\left(\mathrm{CH}_{3} \mathrm{COO}\right)_{2} \underset{-\mathrm{CH}_{3} \mathrm{COO}^{-}}{\stackrel{\mathrm{OH}^{-}}{\longrightarrow}} \mathrm{CH}_{3}
$$<smiles>C[13CH2]CC(=O)O[13CH2]CC(O)O</smiles><smiles>CCC(O)CC[Br+]CC(=O)OC(C)C</smiles>

Outro composto marcado com mercúrio é a 3 - cloromercúrio - 2-metoxipropilureia (neo-hidrina):

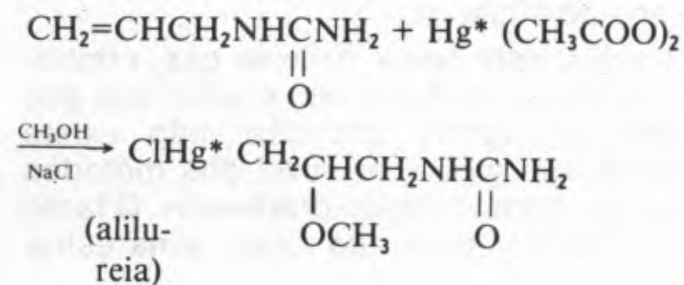

Para terminar, uma referência ao método de marcação por recuo nuclear, de menor interesse prático por conduzir usualmente não só a misturas de vários compostos marcados como também a baixos rendimentos. Se, por exemplo, irradiarmos com neutrões um composto orgânico que contenha azoto este pode ser activado por uma reacção nuclear $(n, p)$ originando ${ }^{14} \mathrm{C}$. Este núclido é, contudo, obtido num estado nuclearmente excitado e altamente ionizado, com quebra de ligações químicas à restante molécula. No processo de desexcitação, o átomo de ${ }^{14} \mathrm{C}$ de recuo pode deslocar um átomo, de carbono ou outro, da estrutura molecular; se for um átomo de carbono deslocado, a estrutura é mantida mas se for um átomo de hidrogénio a ser deslocado obtém-se um novo composto. Dado que átomos nas várias posições podem, em geral, ser deslocados, obtém-se assim uma mistura de produtos marcados. A marcação com ${ }^{14} \mathrm{C}$ por esta técnica requer pois a presença de átomos de azoto, os quais podem fazer parte do próprio composto a irradiar ou, no caso deste não possuir azoto, pode ser um seu derivado azotado (por exemplo, uma amida) ou outro composto contendo azoto que seja deliberadamente adicionado. Por exemplo, irradiando com neutrões uma solução de 2 - metilpirazina em benzeno deu como resultado a formação de tolueno ${ }^{14} \mathrm{C}$. A sua oxidação em ácido benzóico seguida duma degradação de Schmidt mostrou que $86 \%$ da radioactividade se encontrava no grupo metilo e a restante distribuída no anel aromático.

A pequena bibliografia a seguir indicada refere-se principalmente às técnicas de marcação com núclidos radioactivos por métodos químicos e à utilização de compostos marcados em química orgânica, a qual permitirá ao leitor interessado obter informações mais detalhadas sobre estas matérias.

\section{LIVROS}

- A. Murray III, D. L. Williams

Organic synthesis with isotopes (2 vol.), Interscience Publishers (1958).

- V. F. Raaen, G. A. Ropp, H. P. Raaen Carbon 14, McGraw-Hill Co. (1968)

- J. F. Duncan, G. B. Cook Isotopes in Chemistry, Clarendon Press (1968)

- Rodioisotope production and quality control Technical Report Series n. 128, International Atomic Energy Agency (1971)

\section{ARTIGOS DE REVISÃO}

- S. L. THOMAS, H. S. TURNER

The Synthesis of isotopically labelled organic compounds Quarterly Rewiews 7, 407 (1953)

- P. Bévillard

Applications des isotopes à l'étude des structures et mécanismes de réactions.

Bull. Soc. Chim. France D40 (1954)

- D. A. Semenow, J. D. Roberts

Uses of isotopes in organic chemistry

J. Chem. Education 33, 2 (1956)

- F. Weygand, H. Grisebach

Die Anwendung von Isotopen in der organischen Chemie Fortschr. Chem. Forsch, 3, 108 (1954) 